\title{
Changes in Metabolic Profile in the Women with a History of PCOS-A Long-Term Follow-Up Study
}

\author{
Małgorzata Jacewicz-Święcka ${ }^{1, *}$ and Irina Kowalska ${ }^{2}$ \\ 1 Department of Endocrinology, Diabetology and Internal Medicine, Medical University of Bialystok, \\ 15-089 Białystok, Poland \\ 2 Department of Internal Medicine and Metabolic Diseases, Medical University of Bialystok, 15-089 Białystok, \\ Poland; irinak@poczta.onet.pl \\ * Correspondence: malgorzata.ja9@op.pl; Tel.: +48-85-731-8239
}

Received: 11 September 2020; Accepted: 19 October 2020; Published: 20 October 2020

\begin{abstract}
Data concerning metabolic consequences in women with polycystic ovary syndrome (PCOS) are delivered mainly by cross-sectional studies. In this research, we re-examined 31 Caucasian PCOS women after a median period of 120.9 months to evaluate the changes in metabolic syndrome components. Clinical examination, oral glucose tolerance test with estimations of glucose and insulin, lipids, sex hormone-binding globulin (SHBG) and sex hormones assessments were performed on two occasions. Additionally, the euglycaemic hyperinsulinaemic clamp technique was used at the baseline to assess insulin sensitivity (M-clamp value). In the end, the median age of participants was 35. We observed an increase in glucose concentrations, a decrease in insulin concentrations and no changes in insulin resistance markers. Final mean glucose, mean insulin, Matsuda index and body mass index (BMI) were correlated with baseline M-clamp value and SHBG $(p<0.01)$. During the follow-up, no one in the sample developed diabetes. The annualised incidence rate for conversion from normoglycaemia to prediabetes totalled $4.5 \%$. Baseline BMI, free androgen index, fasting glucose and M-clamp value were identified as prediabetes predictors in young PCOS women (respectively, $\mathrm{OR}=1.17, \mathrm{OR}=1.42, \mathrm{OR}=1.2, \mathrm{OR}=0.73, p<0.05$ ). Prediabetes appeared in $76.47 \%$ of the women with a final BMI of $\geq 25 \mathrm{~kg} / \mathrm{m}^{2}$ and in $7.14 \%$ of the normal-weight women ( $\left.p=0.0001\right)$. In conclusion, we report a high rate of adverse change in glucose metabolism in overweight and obese participants, a deterioration in $\beta$-cell function and strong correlations between metabolic parameters assessed in the third and the fourth decade in PCOS women, emphasising the role of early intervention to prevent cardiometabolic diseases.
\end{abstract}

Keywords: PCOS; prediabetes; insulin resistance; metabolic syndrome; longitudinal study

\section{Introduction}

Polycystic ovary syndrome (PCOS) is the most frequent endocrine disorder among women of reproductive age with various prevalence and manifestation among populations [1-3]. In the last few years, different sets of diagnostic criteria were proposed and currently, the revised Rotterdam criteria are recommended [4].

The nature of PCOS is multifactorial and heterogeneous. Environmental factors such as prenatal androgen exposure, poor fetal growth, high carbohydrate consumption and acquired obesity interact with genetic origins and contribute to PCOS pathogenesis [5-9]. It is well established that insulin resistance (IR) and compensatory hyperinsulinaemia are central aetiological abnormalities in women with PCOS which lead to the overproduction of ovarian and adrenal androgens and an increase in androgen bioavailability through inhibition of sex hormone-binding globulin (SHBG) secretion [10]. The prevalence of IR in women with PCOS is estimated at 50-70\% [11], or according to another source, 
even as high as $75 \%$ in lean and $95 \%$ in overweight women [12]. However, the proper assessment is difficult due to the fact that IR is assessed using different methods. Cassar et al. in a meta-analysis of 28 articles concerning insulin sensitivity estimated with the euglycaemic hyperinsulinaemic clamp found that IR is the intrinsic feature of PCOS and that insulin sensitivity is $27 \%$ lower in women with PCOS compared to controls, independently of body mass index (BMI) [13]. The importance of insulin resistance phenomenon regardless of body weight was provided by several authors $[14,15]$.

IR and hyperandrogenism (HA) along with insulin secretory defects, post-receptor defect in insulin signalling, low-grade inflammation, high carbohydrate consumption, hypothalamic-pituitary axis abnormalities and disrupted folliculogenesis contribute to the reproductive and metabolic dysfunctions in PCOS $[5,10,16-18]$. It has been described that obesity is threefold more prevalent in women with PCOS compared to healthy women [19]. Obesity synergistically with PCOS increases IR and hyperinsulinaemia $[20,21]$ and affects worse metabolic prognosis [21,22]. The development of glucose abnormalities is a multifactorial process that can develop in PCOS subjects from adolescence [23] and may be exacerbated by ageing [24]. It has been found that even non-obese and young women with PCOS have a higher risk of prediabetes (preDM), diabetes mellitus type 2 (T2DM) and gestational diabetes mellitus compared to age- and weight-matched women without PCOS $[25,26]$. The prevalence of impaired glucose tolerance (IGT) and T2DM in PCOS patients totals $23-35 \%$ and $4-10 \%$, respectively [18]. Furthermore, although obesity affects lipid profile, PCOS seems to be a completely independent risk factor of dyslipidaemia [27] which affects 70\% of patients [28]. Elevated triglycerides (TG) and decreased high-density lipoprotein cholesterol (HDL-c) seem to be the most common pattern in PCOS [29]. There is also evidence that arterial hypertension $(\mathrm{AH})$ is significantly more prevalent in premenopausal women with PCOS compared to the general population [30,31]. Consequently, the prevalence of metabolic syndrome (MetS) is found to be at least threefold higher in women with PCOS compared to general population [32] and is estimated at $33 \%$ to $47 \%$ [18,33]. Interestingly, although PCOS patients have a proven increased prevalence of cardiovascular disease risk factors, the risk of cardiovascular morbidity and mortality is still equivocal [34,35]. To explain this phenomenon, longitudinal studies with PCOS women should be conducted. The knowledge of the pace, the nature of the metabolic changes and the interrelationships between them in women with PCOS could be of key importance for the explanation of dissonance between the expected and observed cardiovascular outcomes.

Although a lot of reports concerning metabolic consequences in PCOS have been published, almost all of them were designed as cross-sectional studies. There is a paucity of studies with long-term follow-up in which the detailed metabolic profile in women with PCOS was re-evaluated [35] and therefore, the course and development of metabolic disorders as well as the factors which impact on the subsequent complications in women with PCOS are poorly explored. The main aim of the present study was to determine the impact of ageing on glucose metabolism, insulin sensitivity, anthropometric parameters, lipid profile and values of blood pressure (BP) in a cohort of 31 women with previously diagnosed PCOS according to the Rotterdam criteria. Additionally, connections between anthropometric, metabolic and biochemical parameters assessed at an interval of ten years were investigated among subjects and risk factors for preDM in PCOS were identified. The data obtained would assist clinicians in the assessment and management of risk in women with PCOS.

\section{Materials and Methods}

\subsection{Study Population}

Ninety-one potentially eligible women diagnosed with PCOS in the Outpatient Endocrinology and Gynaecology Clinics in Białystok between 2003 and 2009 were identified from records to participate in the study. Only patients with correct results of an oral glucose tolerance test (OGTT) at baseline were taken under consideration in the follow-up study. Unfortunately, no contact was found with thirty-four subjects because of the invalid address, phone number and surname. Fifty-seven women were contacted by phone for re-evaluation and twenty-six of them were excluded, because they refused 
participation in the study due to living too far away from Białystok $(n=19)$, they were pregnant or within 12 months of delivery $(n=3)$, in case of malnutrition $(n=1)$, chronic or acute infection (within the previous 30 days) $(n=1)$, history of neoplasm or other serious medical problem $(n=2)$. Finally, thirty-one Caucasian women were included in the analysis. The median age at the baseline was 25.53 years (interquartile range (IQr) $=21.51-29.22)$. The studied cohort $(n=31)$ and the women who did not participate in the follow-up examination $(n=60)$ did not differ statistically significantly with regard to age, BMI and waist circumference (all $p>0.05$ ).

\subsection{Baseline Study}

When first examined, the diagnosis of PCOS was made according to the Rotterdam criteria [4] - minimum two out of three criteria were fulfilled: oligomenorrhoea/amenorrhea (OM/AM), polycystic ovarian morphology $(\mathrm{PCOM})$ in ultrasound examination, hirsutism ( $>8$ according to modified Ferriman-Gallwey score (mFGS)) or increased testosterone (TT)/free androgen index (FAI), after exclusion of related disorders. The recruitment, clinical examination, anthropometric measurements, bioelectric impedance analysis, an OGTT, lipids and sex hormone assessments were performed as described previously [36]. Median values of sex hormones totalled: $\mathrm{TT}=0.63 \mathrm{ng} / \mathrm{mL}$ $(\mathrm{IQr}=0.46-0.88), \mathrm{FAI}=4.63(\mathrm{IQr}=3.67-10.3)$, luteinizing hormone $=7.8 \mathrm{mIU} / \mathrm{mL}(\mathrm{IQr}=4.9-10.8)$. A total of 22 women $(71 \%)$ presented classic phenotype A (PCOM + OM + HA), 7 women presented phenotype $\mathrm{D}(\mathrm{PCOM}+\mathrm{OM})$, one person presented phenotype $\mathrm{B}(\mathrm{OM}+\mathrm{HA})$ and one person presented phenotype $\mathrm{C}(\mathrm{PCOM}+\mathrm{HA})$. Insulin sensitivity was measured with a euglycaemic hyperinsulinaemic clamp technique according to DeFronzo et al. [37]. The rate of whole-body glucose uptake was calculated as the mean glucose infusion rate from 80 to $120 \mathrm{~min}$, corrected for glucose space and normalised per kilogram of fat-free mass (M-clamp value) [38].

\subsection{Ethical Approval}

Before conducting the study, all participants were provided informed and written consent after full explanation of the purpose and nature of all procedures used. The study protocol was approved by the Ethics Committee of the Medical University of Białystok and followed the principles of the Declaration of Helsinki (reference no. R-I-002/347/2015; date of approval 24.09.2015).

\subsection{Follow-Up Study}

Between December 2015 and May 2017 thirty-one women were re-evaluated and baseline tests were repeated.

\subsubsection{Protocol of the Study}

The comprehensive questionnaire, physical examination, anthropometric measurements, transvaginal ultrasound scans, bioelectrical impedance analysis, blood collection for biochemical tests, an OGTT were all performed on the same day in each woman, 3-5 days after spontaneous menstrual bleeding or at random in the presence of AM (after excluding pregnancy using appropriate test). All the participants declared that they had not received treatment with oral contraceptives, antiandrogens, insulin sensitizers or any other medication known to affect sex hormones or carbohydrate metabolism for at least three months before an examination. No woman had a diagnosis of preDM or T2DM before being submitted to an OGTT.

\subsubsection{Clinical Evaluation and Anthropometric Measurements}

Thirty-one women completed a clinic visit during which anamnesis and physical examination were conducted by the same physician in all the participants. Detailed interview according to the special questionnaire was collected and data about menstruation, reproductive history, current and 
previous diseases, smoking, medication use, family history of T2DM, cardio-vascular diseases and neoplasm ( $\geq 1 \mathrm{~s}$ degree relative) were obtained.

Body height was measured with a Harpenden Stadiometer (Tanita, Tokyo, Japan) without shoes to $0.1 \mathrm{~cm}$ and body mass was measured with underwear on an electronic scale to $0.1 \mathrm{~kg}$. BMI was calculated as the ratio of body mass in kilograms $(\mathrm{kg})$ and height in meters squared $\left(\mathrm{m}^{2}\right)$. Waist circumference (WC) was measured with subjects standing, using a 1-cm-wide outstretched measuring tape, to the nearest 0.0 or $0.5 \mathrm{~cm}$ midway between the lowest rib margin and an iliac crest [39]. The waist-to-hip ratio (WHR) was calculated. Arterial BP was measured with an electronic sphygmomanometer after women were sitting for at least $15 \mathrm{~min}$ and recorded data were the mean of two consecutive measurements performed at a 15-min interval. The presence of hirsutism, acne and androgenic alopecia was verified.

\subsubsection{Image Tests}

Ovary ultrasound scans were performed for all the women (Voluson 730 Expert, GE Healthcare, Zipf, Austria). Fat mass (\%) was assessed by multi-frequency bioelectrical impedance analysis using the InBody 770 Body Composition Analyzer (Biospace, Beverly Hills, CA, USA) in all participants.

\subsubsection{Biochemical Analyses}

Blood samples were drawn after an overnight fast between 08.00 and $09.00 \mathrm{am}$ and were either analysed immediately or stored at $-80^{\circ} \mathrm{C}$ until analysed. A standardised 75-g OGTT was performed. Blood samples for measurements of serum insulin and plasma glucose were taken at baseline, 30,60,120 min after glucose ingestion. Plasma glucose concentrations were assessed by the hexokinase method. Serum insulin concentrations were assessed with the immunoradiometric method (DIAsource ImmunoAssays S.A., Belgium) (minimum detectable concentration (MDC): $1 \mu \mathrm{IU} / \mathrm{mL}$; intra-assay coefficient of variation (CV) - below 2.2\%, inter-assay CV-below 6.5\%). There is no cross-reaction between human and animal proinsulins in this method. Fasting blood samples were used to assay glycated haemoglobin (HbA1c), SHBG, lipid and hormonal profile. HbA1c level was measured using high-performance liquid chromatography (Bio Rad, Hercules, California, United States). Plasma lipid concentrations (total cholesterol (TC), HDL-c, TG) were measured by enzymatic colorimetric method (Cobas c111, Roche Diagnostic Ltd., Switzerland). SHBG concentration was assessed with immunoradiometric method (DIAsource ImmunoAssays S.A., Angleur, Belgium) (intra-assay and inter-assay CV for SHBG: 5.2\% and 5.8\%). Serum concentrations of TT, dehydroepiandrosterone sulfate (DHEAS), androstenedione (A4) and 17-hydroxprogesterone (17-OHP) were measured with radioimmunoassay (DIAsource ImmunoAssays S.A., Belgium) (MDC for TT: $0.05 \mathrm{ng} / \mathrm{mL}$, for DHEAS: $1.23 \mu \mathrm{g} / \mathrm{dL}$, for A4: $0.03 \mathrm{ng} / \mathrm{mL}$, for 17-OHP: $0.03 \mathrm{ng} / \mathrm{mL}$; intra-assay and inter-assay CV for TT: 3.3\% and $4.8 \%$, for DHEAS: $3.6 \%$ and $6.5 \%$, for A4: $3.2 \%$ and $5.9 \%$, for $17-\mathrm{OHP}: 6.8 \%$ and $10.7 \%$ ).

\subsubsection{Calculations}

IR was estimated using the homeostasis model assessment (HOMA) according to the following formula: (fasting serum insulin $(\mu \mathrm{IU} / \mathrm{mL}) \times$ fasting plasma glucose $(\mathrm{mmol} / \mathrm{L})) / 22.5$ [40], with a threshold of at least 2.5. Matsuda index was calculated using the validated calculator [41] and the values $\leq 2.5$ indicated on IR. HOMA $\beta$-cell function (HOMA- $\% \beta$ ) was evaluated according to the formula: $(20 \times$ fasting insulin $(\mu \mathrm{IU} / \mathrm{mL})) /($ fasting plasma glucose $(\mathrm{mmol} / \mathrm{L})-3.5)[40]$. $\beta$-cell function was assessed also with the insulinogenic index (IGI) and calculated as (30 min insulin $(\mu \mathrm{IU} / \mathrm{mL})$ - fasting insulin $(\mu \mathrm{IU} / \mathrm{mL})) /(30 \mathrm{~min}$ glucose $(\mathrm{mg} / \mathrm{dL})$-fasting glucose $(\mathrm{mg} / \mathrm{dL}))$. FAI was calculated as serum $(\mathrm{TT}(\mathrm{nmol} / \mathrm{L}) \times 100) /$ SHBG $(\mathrm{nmol} / \mathrm{L})$ [42]. Plasma low-density lipoprotein cholesterol (LDL-c) was calculated according to Friedewald's formula. 


\subsubsection{Statistical Analysis}

All analysed variables were tested for normality of distribution using the Lilliefors (Kolomorov-Smirnov) and Shapiro-Wilk tests. Due to the non-normal distribution of the data, all values were expressed as median (interquartile range). Comparisons between the groups were evaluated with non-parametric Mann-Whitney U-test. Wilcoxon signed-rank tests and the sign test were used to compare estimated variables at baseline and after follow-up. Correlation analysis was performed using the Spearman test. Chi-square test was used to determine the between-group differences of categorical variables. Afterwards, logistic regression methods were used to assess which factors determined at baseline study predict prediabetes found at the end of a 10-year follow-up period. A $p$-value $<0.05$ was considered statistically significant. The statistical analysis for the present study was performed with the Statistica package (Statistica 13.3, Statsoft, Cracow, Poland) and Stata/IC 12.1 (StataCorp LP).

\subsubsection{Definitions}

PCOS was diagnosed as the presence of a minimum two out of the following conditions: clinical and/or biochemical HA, OM or AM, PCOM assessed on transvaginal ultrasound $[4,43]$. Clinical HA was assessed on the basis of hirsutism (mFGS $>8$ ), acne or androgenic alopecia. Biochemical HA was defined as TT $\geq 70 \mathrm{ng} / \mathrm{dL}$ and/or FAI $\geq 5$ and/or A4 $>3 \mathrm{ng} / \mathrm{mL}$, and/or serum DHEAS above the level recommended for the respective age group. OM was defined as menstrual cycle intervals $\geq 35$ days or $<8$ cycles per year, while AM as menstrual cycle length $>90$ days. Related disorders like thyroid dysfunction, hyperprolactinaemia, ovary tumours and non-classic congenital adrenal hyperplasia were excluded by appropriate testing.

Women were categorized into BMI groups for normal weight $\left(18.5-24.9 \mathrm{~kg} / \mathrm{m}^{2}\right)$, overweight $\left(25.0-29.9 \mathrm{~kg} / \mathrm{m}^{2}\right)$ and obese $\left(B M I \geq 30.0 \mathrm{~kg} / \mathrm{m}^{2}\right)$ [44]. AH was defined as mean systolic BP (SBP) $\geq 140 \mathrm{mmHg}$ or mean diastolic BP (DBP) $\geq 90 \mathrm{mmHg}$ or the use of antihypertensive medications. PreDM referred to impaired fasting glucose (IFG) when the fasting plasma glucose levels were $100-125 \mathrm{mg} / \mathrm{dL}$ and IGT when the 2-h plasma glucose values in an OGTT were $140-199 \mathrm{mg} / \mathrm{dL}$. T2DM was defined as fasting plasma glucose $\geq 126 \mathrm{mg} / \mathrm{dL}$, or the 2 -h plasma glucose $\geq 200 \mathrm{mg} / \mathrm{dL}$ [45]. Dyslipidaemia includes hypercholesterolaemia (LDL-c $\geq 115 \mathrm{mg} / \mathrm{dL}$ or non-HDL-c $>145 \mathrm{mg} / \mathrm{dL}$ ), hypertriglyceridaemia (TG $\geq 150 \mathrm{mg} / \mathrm{dL})$, low concentration of HDL-c $(<50 \mathrm{mg} / \mathrm{dL})$ or use of cholesterol-lowering medications. MetS was defined according to the International Diabetes Federation [46]. The diagnosis of MetS necessarily requires elevated $W C(\geq 80 \mathrm{~cm})$ and positivity in $\geq 2$ of 4 criteria, namely: elevated BP (SBP $\geq 130 \mathrm{mmHg}$ or $\mathrm{DBP} \geq 85 \mathrm{mmHg}$ or antihypertensive drug treatment), reduced HDL-c ( $<50 \mathrm{mg} / \mathrm{dL}$ or the use of cholesterol-lowering drugs), elevated TG ( $\geq 150 \mathrm{mg} / \mathrm{dL}$ or specific drug treatment), and elevated blood glucose (IFG, IGT, T2DM).

\section{Results}

The median duration of the follow-up period was 120.9 months ( $\mathrm{IQr}=107.17-127.38)$. The median age which was reached at the end of the observation was 35 years $(\mathrm{IQr}=31.2-39.8)$.

\subsection{Anthropometric Parameters}

During the observation median values of BMI and WC increased significantly in the entire group (Table 1). 
Table 1. Characteristics of the participants at the beginning and at the end of follow-up $(n=31)$.

\begin{tabular}{|c|c|c|c|}
\hline Characteristic & Baseline & Follow-Up & $p$-Value \\
\hline Age (years) & $25.53(21.51-29.22)$ & $35.00(31.20-39.80)$ & $<0.00001$ \\
\hline Body mass $(\mathrm{kg})$ & $70.0(58.0-90.0)$ & $72.2(59.7-92.6)$ & 0.002 \\
\hline BMI $\left(\mathrm{kg} / \mathrm{m}^{2}\right)$ & $25.61(21.48-31.42)$ & $26.60(21.76-34.29)$ & 0.001 \\
\hline Waist Circumference (cm) & $79.0(71.0-97.0)$ & $90.0(77.0-110.0)$ & $<0.00001$ \\
\hline Waist to Hip Ratio & $0.81(0.77-0.85)$ & $0.89(0.85-0.95)$ & 0.00006 \\
\hline Fat Mass (kg) & $24.15(15.96-35.15)$ & $24.30(16.44-37.50)$ & 0.04 \\
\hline Fat Mass (\%) & $34.0(27.5-44.0)$ & $32.7(26.47-45.0)$ & NS \\
\hline Free Fat Mass (kg) & $45.15(42.24-50.76)$ & $46.10(44.0-55.5)$ & 0.002 \\
\hline Triglycerides (mg/dL) & $82(61-135)$ & $71(57-119)$ & NS \\
\hline Total Cholesterol (mg/dL) & $179(158-208)$ & $196(180-214)$ & NS \\
\hline LDL-c (mg/dL) & $93(78.2-134.2)$ & $104(98.4-113.6)$ & NS \\
\hline HDL-c (mg/dL) & $58.2(51-69)$ & $68.0(48-79)$ & 0.07 \\
\hline Systolic Blood Pressure (mmHg) & $120(110-125)$ & $124(111-130)$ & 0.08 \\
\hline Diastolic Blood Pressure (mmHg) & $80(70-80)$ & $78(72-82)$ & NS \\
\hline Normal Weight $n(\%)$ & $14(45 \%)$ & $14(45 \%)$ & NS \\
\hline Overweight $n(\%)$ & $8(25.86 \%)$ & $5(16.129 \%)$ & NS \\
\hline Obesity $n(\%)$ & $9(29 \%)$ & $12(38.709 \%)$ & NS \\
\hline $\begin{array}{c}\text { Abdominal Obesity } \\
\text { (waist circumference } \geq 80 \mathrm{~cm}) n(\%)\end{array}$ & $15(48 \%)$ & $23(74 \%)$ & 0.04 \\
\hline Hypertriglyceridaemia $n(\%)$ & $5(16.129 \%)$ & $5(16.129 \%)$ & NS \\
\hline Hypercholesterolaemia $n(\%)$ & $9(29 \%)$ & $7(22.58 \%)$ & NS \\
\hline Low HDL-cholesterol $n(\%)$ & $7(22.58 \%)$ & $8(25.8 \%)$ & NS \\
\hline Metabolic syndrome $n(\%)$ & $6(19.35 \%)$ & $11(35.48 \%)$ & NS \\
\hline
\end{tabular}

Data are expressed as median (25-75\% quartiles) or numbers (\%). $p<0.05$ was considered statistically significant. Wilcoxon signed-rank test and the sign test were used to compare variables at baseline and after follow-up. BMI, body mass index; HDL-c, high-density lipoprotein cholesterol; LDL-c, low-density lipoprotein cholesterol; NS, non-significant.

It was noted that $94.12 \%$ of the women who in the past had a BMI of $\geq 25 \mathrm{~kg} / \mathrm{m}^{2}$ remained overweight or obese, and similarly $92.86 \%$ of the women with BMI $<25 \mathrm{~kg} / \mathrm{m}^{2}$ in the past remained normal weight after the follow-up period $(p<0.0001)$. However, $50 \%$ of the women with $\mathrm{WC}<80 \mathrm{~cm}$ at the baseline finally developed abdominal obesity, while no woman with $\mathrm{WC} \geq 80 \mathrm{~cm}$ normalised this parameter over time $(p<0.05)$. The characteristics of the women according to their final BMI are presented in Table 2.

Table 2. Metabolic characteristics of the participants according to BMI group.

\begin{tabular}{|c|c|c|c|}
\hline Characteristic & $\begin{array}{c}\mathrm{BMI}<25 \mathrm{~kg} / \mathrm{m}^{2} \\
(n=14)\end{array}$ & $\begin{array}{c}\mathrm{BMI} \geq 25 \mathrm{~kg} / \mathrm{m}^{2} \\
(n=17)\end{array}$ & $p$-Value \\
\hline Age at Follow-up (years) & $34.15(30.2-35.0)$ & $38.3(34.4-43.8)$ & 0.01 \\
\hline BMI at Follow-up $\left(\mathrm{kg} / \mathrm{m}^{2}\right)$ & $21.62(20.32-22.87)$ & $33.24(28.83-39.12)$ & $<0.00001$ \\
\hline BMI at Baseline $\left(\mathrm{kg} / \mathrm{m}^{2}\right)$ & $21.47(19.66-21.94)$ & $31.05(27.82-36.29)$ & $<0.00001$ \\
\hline$\Delta \mathrm{BMI}\left(\mathrm{kg} / \mathrm{m}^{2}\right)$ & $0.67(-0.71-1.18)$ & $2.88(1.14-4.04)$ & 0.01 \\
\hline Waist Circumference at Follow-Up (cm) & $77(72-84)$ & $109(95-122)$ & $<0.00001$ \\
\hline Waist Circumference at Baseline $(\mathrm{cm})$ & $71(68-74)$ & $93(85-103)$ & $<0.00001$ \\
\hline$\Delta$ Waist Circumference $(\mathrm{cm})$ & $4.5(0-10)$ & $13(8-19)$ & 0.01 \\
\hline Waist To Hip Ratio at Follow-Up & $0.84(0.79-0.88)$ & $0.93(0.90-0.97)$ & 0.0001 \\
\hline Waist To Hip Ratio at Baseline & $0.78(0.74-0.81)$ & $0.85(0.80-0.88)$ & 0.006 \\
\hline Fat Mass At Follow-Up (\%) & $26.14(22.1-30.5)$ & $43.4(37.5-48.4)$ & $<0.00001$ \\
\hline Fat Mass At Baseline (\%) & $27.1(23.0-29.6)$ & $42(37.0-46.5)$ & $<0.00001$ \\
\hline Glucose $0^{\prime}$ at Follow-up (mg/dL) & $89.5(85-90)$ & $102(96-107)$ & 0.00008 \\
\hline Glucose $0^{\prime}$ at Baseline $(\mathrm{mg} / \mathrm{dL})$ & $81.5(77-86.1)$ & $86(81-91)$ & 0.06 \\
\hline Glucose $120^{\prime}$ at Follow-Up (mg/dL) & $91.5(77-99)$ & $125(100-152)$ & 0.001 \\
\hline Glucose $120^{\prime}$ at Baseline $(\mathrm{mg} / \mathrm{dL})$ & $72.5(66-83.9)$ & $100(94-123)$ & 0.006 \\
\hline Mean Glucose at Follow-Up (mg/dL) & $100(94-109.5)$ & $147(123.75-150.75)$ & 0.00009 \\
\hline Mean Glucose at Baseline (mg/dL) & $94.79(86.75-104.5)$ & $114.75(102.25-125.75)$ & 0.005 \\
\hline Insulin $0^{\prime}$ at Follow-Up (uIU/mL) & $6.16(5.09-8.20)$ & $16.33(11.54-19.57)$ & 0.00002 \\
\hline
\end{tabular}


Table 2. Cont.

\begin{tabular}{|c|c|c|c|}
\hline Characteristic & $\begin{array}{c}\mathrm{BMI}<25 \mathrm{~kg} / \mathrm{m}^{2} \\
(n=14)\end{array}$ & $\begin{array}{c}\mathrm{BMI} \geq 25 \mathrm{~kg} / \mathrm{m}^{2} \\
(n=17)\end{array}$ & $p$-Value \\
\hline Insulin $0^{\prime}$ at Baseline-Up (uIU/mL) & $9.7(7.07-13.94)$ & $18.5(11.70-25.34)$ & 0.02 \\
\hline Insulin $120^{\prime}$ at Follow-Up (uIU/mL) & $27.9(18.09-31.82)$ & $75.73(33.57-149.26)$ & 0.0009 \\
\hline Insulin $120^{\prime}$ at Baseline $(\mathrm{uIU} / \mathrm{mL})$ & $27.56(14.58-53.75)$ & $84.67(42.82-117.60)$ & 0.01 \\
\hline Mean Insulin at Follow-Up (uIU/mL) & $35.59(28.91-45.61)$ & $88.04(52.66-107.55)$ & 0.00006 \\
\hline Mean Insulin at Baseline (uIU/mL) & $44.31(36.27-63.26)$ & $94.33(67.47-116.93)$ & 0.0009 \\
\hline M-Clamp Value At Baseline (mg/kgffm/min) & $10.78(8.71-12.13)$ & $5.83(4.17-8.32)$ & 0.0002 \\
\hline Matsuda Index at Follow-Up & $6.27(5.62-7.32)$ & $1.99(1.7-3.06)$ & $<0.00001$ \\
\hline Matsuda Index at Baseline & $4.93(4.02-7.15)$ & $2.45(1.79-3.4)$ & 0.0007 \\
\hline HOMA-IR Score at Follow-Up & $1.36(1.08-1.77)$ & $3.87(2.71-5.07)$ & $<0.00001$ \\
\hline HOMA-IR Score at Baseline & $2.15(1.35-2.66)$ & $3.98(2.51-5.54)$ & 0.006 \\
\hline HOMA-\%B at Follow-Up & $86.13(73.31-115.16)$ & $137.04(95.96-192.38)$ & 0.009 \\
\hline HOMA-\%B at Baseline & $212.98(164.77-288)$ & $254.01(175.5-349.2)$ & NS \\
\hline Triglycerides at Follow-Up (mg/dL) & $57(48-63)$ & $113(83-186)$ & 0.00001 \\
\hline Triglycerides at Baseline (mg/dL) & $69.5(48.6-82)$ & $118(76-155)$ & 0.01 \\
\hline LDL-c at Follow-Up (mg/dL) & $99.4(77.6-110)$ & $112.4(103.8-132.2)$ & 0.006 \\
\hline LDL-c at Baseline $(\mathrm{mg} / \mathrm{dL})$ & $92.9(78.2-105.18)$ & $99(86-139.8)$ & NS \\
\hline HDL-c at Follow-Up (mg/dL) & $73.5(69-100)$ & $50(43-66)$ & 0.0007 \\
\hline HDL-c at Baseline (mg/dL) & $67.1(58.2-74)$ & $53(42-63)$ & 0.002 \\
\hline Systolic Blood Pressure At Follow-Up (mmHg) & $121(110-124)$ & $126(117-135)$ & 0.04 \\
\hline Systolic Blood Pressure At Baseline (mmHg) & $120(110-120)$ & $125(110-130)$ & NS \\
\hline Diastolic Blood Pressure At Follow-Up (mmHg) & $75(65-78)$ & $79(76-84)$ & 0.03 \\
\hline Diastolic Blood Pressure At Baseline (mmHg) & $72.5(70-80)$ & $80(70-80)$ & NS \\
\hline SHBG at Follow-up (nmol/l) & $56.71(44.79-105.09)$ & $35.54(23.36-66.32)$ & 0.02 \\
\hline SHBG at Baseline (nmol/l) & $60.85(45.13-64.47)$ & $27.20(20.03-38.88)$ & 0.0009 \\
\hline FAI at Follow-Up & $2.20(1.36-5.98)$ & $2.80(2.20-9.50)$ & NS \\
\hline FAI at Baseline & $4.11(3.44-5.24)$ & $8.83(4.05-10.73)$ & 0.04 \\
\hline 17-OHP at Follow-Up (ng/mL) & $1.52(1.25-1.72)$ & $1.05(0.75-1.24)$ & 0.008 \\
\hline
\end{tabular}

Data are expressed as median (25-75\% quartiles). $p<0.05$ was considered statistically significant. $p$-value refers to differences between the two BMI groups. Variables were analysed by Mann-Whitney U-test. BMI, body mass index; FAI, free androgen index; HDL-c, high-density lipoprotein cholesterol; HOMA-IR, homeostasis model assessment of insulin resistance; HOMA- $\% \beta$, homeostasis model assessment of $\beta$-cell dysfunction; LDL-c, low-density lipoprotein cholesterol; M-clamp value, insulin sensitivity estimated with the euglycaemic hyperinsulinaemic clamp technique; NS, non-significant; SHBG, sex hormone-binding globulin; 17-OHP, 17-hydroxyprogesterone.

Correlations were found between the final values of anthropometric parameters and baseline metabolic parameters (Table 3). Moreover, it is worth mentioning connections between anthropometric parameters and androgens assessed at the final examination. It was noted that BMI, WC and fat mass (\%) were correlated with FAI (respectively, $\mathrm{R}=0.38, \mathrm{R}=0.4, \mathrm{R}=0.4$, all $p<0.05$ ), and BMI was correlated with 17-OHP $(\mathrm{R}=-0.36, p<0.05)$. A positive correlation was found between $\Delta \mathrm{BMI}$ and $\triangle \mathrm{FAI}$, whereas a negative correlation was found between $\triangle \mathrm{BMI}$ and $\triangle$ SHBG (respectively, $\mathrm{R}=0.39$, $\mathrm{R}=-0.40$, all $p<0.05$ ).

Table 3. Correlations between final and baseline anthropometric and metabolic parameters.

\begin{tabular}{|c|c|c|c|}
\hline \multirow{2}{*}{ Parameters at the Baseline Examination } & \multicolumn{3}{|c|}{ Parameters at the Follow-Up } \\
\hline & BMI $\left(\mathrm{kg} / \mathrm{m}^{2}\right)$ & Waist Circumference (cm) & Body Fat (\%) \\
\hline BMI $\left(\mathrm{kg} / \mathrm{m}^{2}\right)$ & $0.94^{* * *}$ & $0.88^{* * *}$ & $0.85^{* * *}$ \\
\hline Waist Circumference $(\mathrm{cm})$ & $0.88^{* * *}$ & $0.88^{* * *}$ & $0.82 * * *$ \\
\hline Fat Mass $(\%)$ & $0.89^{* * *}$ & $0.85^{* * *}$ & $0.87^{* * *}$ \\
\hline Glucose $0^{\prime}(\mathrm{mg} / \mathrm{dL})$ & $0.35^{p=0.05}$ & $0.32^{p=0.08}$ & $0.40 *$ \\
\hline Mean Glucose (mg/dL) & $0.42 *$ & $0.45 *$ & $0.51 * *$ \\
\hline Insulin $0^{\prime}(\mathrm{uIU} / \mathrm{mL})$ & $0.51^{* *}$ & $0.51 * *$ & $0.60^{* * *}$ \\
\hline Mean Insulin (uIU/mL) & $0.61^{* * *}$ & $0.58^{* * *}$ & $0.72 * * *$ \\
\hline M-Clamp Value (mg/kgffm/min) & $-0.68 * * *$ & $-0.65^{* * *}$ & $-0.70 * * *$ \\
\hline Matsuda Index & $-0.62 * * *$ & $-0.61^{* * *}$ & $-0.75^{* * *}$ \\
\hline HOMA-IR Score & $0.59 * * *$ & $0.59 * * *$ & $0.66^{* * *}$ \\
\hline Triglycerides (mg/dL) & $0.55^{* *}$ & $0.46^{* *}$ & $0.56^{* * *}$ \\
\hline HDL-c (mg/dL) & $-0.55^{* *}$ & $-0.49^{* *}$ & $-0.53^{* *}$ \\
\hline SHBG (nmol/l) & $-0.52 * *$ & $-0.43 *$ & $-0.56^{* *}$ \\
\hline
\end{tabular}

Data are shown as $\mathrm{r}$ correlation coefficient. Significance levels are indicated by asterisks $\left({ }^{*}, p<0.05 ;{ }^{* *}, p<0.01\right.$; $* * *, p<0.001)$. Correlation coefficients were estimated by Spearman's correlation for all parameters. BMI, body mass index; HDL-c, high-density lipoprotein cholesterol; HOMA-IR, homeostasis model assessment of insulin resistance; M-clamp value, insulin sensitivity estimated with the euglycaemic hyperinsulinaemic clamp technique; SHBG, sex hormone-binding globulin. 


\subsection{Blood Pressure}

Median values of SBP and DBP did not change significantly in the entire group, however, three women developed $\mathrm{AH}$ and were taking antihypertensive medicines. Significantly higher values of SBP and DBP were found in the women with BMI $\geq 25 \mathrm{~kg} / \mathrm{m}^{2}$ compared to the normal weight participants (Table 2), in the women with Matsuda-IR compared to the women without IR (respectively, $132 \mathrm{vs.}$ $122 \mathrm{mmHg}, 81 \mathrm{vs} .76 \mathrm{mmHg}$, all $p<0.05$ ), and in the women with OM compared to the women with regular menstrual cycles (130 vs. $121 \mathrm{mmHg}, 79$ vs. $76 \mathrm{mmHg}$, all $p<0.05$ ).

$\mathrm{BP}$ values were correlated with final anthropometric parameters (BMI, WC, WHR, fat mass \%), insulin concentrations and IR indices (all $p<0.05)$. WC and fat mass $(\%)$ were the only metabolic parameters assessed at the baseline that were significantly correlated with final values of SBP (respectively, $\mathrm{R}=0.49, p=0.006 ; \mathrm{R}=0.38, p=0.03$ ), while fat mass (\%) was the only metabolic parameter assessed at the baseline that was correlated with final values of DBP $(R=0.42, p=0.02)$.

\subsection{Lipids}

TC, LDL-c, HDL-c and TG concentrations, as well as the percentages of patients with hypertriglyceridaemia, hypercholesterolaemia or low concentration of HDL-c, did not change markedLy in the entire group (Table 1). Abnormal lipid profile (elevated LDL-c or TG or lowered HDL-c) was found in $69 \%$ of the women who had had abnormal lipid profile and in $22 \%$ of the women who had had normal lipid concentrations at the baseline $(p=0.009)$. Disturbed lipid profile was detected in $70.59 \%$ of the women with BMI $\geq 25 \mathrm{~kg} / \mathrm{m}^{2}$ and in $7.14 \%$ of normal weight women ( $\left.p=0.0004\right)$. Interestingly, lowered concentration of HDL-c was noted only in overweight or obese women. Furthermore, abnormal lipid profile was found in no woman with WC $<80 \mathrm{~cm}$ and in $57 \%$ of the women with abdominal obesity $(p=0.005)$. TG, HDL-c and non-HDL-c determined at the end of the follow-up were correlated with final BMI (respectively, $\mathrm{R}=0.78, \mathrm{R}=-0.68, \mathrm{R}=0.71$, all $p<0.0001$ ), WC (respectively, $\mathrm{R}=0.77, \mathrm{R}=-0.63, \mathrm{R}=0.7$, all $p<0.001$ ), SHBG (respectively, $\mathrm{R}=-0.55, \mathrm{R}=0.57$, $\mathrm{R}=-0.61$, all $p<0.001$ ) and FAI (respectively, $\mathrm{R}=0.41, p=0.02 ; \mathrm{R}=-0.51, p=0.003 ; \mathrm{R}=0.52$, $p=0.003$ ), but also with baseline BMI (respectively, $\mathrm{R}=0.79, \mathrm{R}=-0.63, \mathrm{R}=0.68$, all $p<0.001$ ) and WC (respectively, $\mathrm{R}=0.82, \mathrm{R}=-0.62, \mathrm{R}=0.68$, all $p<0.001$ ). Interestingly, a low concentration of HDL-c was found in $42.11 \%$ of the women who had had biochemical HA at the baseline and in no one who had had not biochemical HA in the past $(p=0.009)$. Furthermore, lipids were also correlated with glucose, insulin and markers of IR (data depicted in the chapter "OGTT and IR").

\subsection{Glycaemic Status and Insulin Resistance}

\subsubsection{OGTT and IR}

No one of the participants ever used antidiabetics except metformin, however, at the final examination, no one declared taking metformin in the last year. After the follow-up all the concentrations of glucose determined during an OGTT increased significantly in the entire group, while all the concentrations of insulin decreased, however, only fasting insulin, 30-min insulin and HOMA- $\% \beta$ changed significantly. Interestingly, there were no significant changes in IR indices, like HOMA-IR score and Matsuda index in the examined participants and the percentage of the women with a diagnosis of IR decreased slightly. Changes in glucose metabolism in the entire group are presented in Table 4 . 
Table 4. Differences in glucose metabolism variables between baseline and follow-up investigations $(n=31)$.

\begin{tabular}{cccc}
\hline Characteristic & Baseline & Follow-Up & $p$-Value \\
\hline Glucose $0^{\prime}(\mathrm{mg} / \mathrm{dL})$ & $85(80-89)$ & $94(89-103)$ & $<0.00001$ \\
Glucose $30^{\prime}(\mathrm{mg} / \mathrm{dL})$ & $131(123-152)$ & $144(125-169)$ & 0.02 \\
Glucose 60' $(\mathrm{mg} / \mathrm{dL})$ & $108(91.6-137)$ & $139(97-166)$ & 0.003 \\
Glucose $120^{\prime}(\mathrm{mg} / \mathrm{dL})$ & $89(70.5-102)$ & $100(88-131)$ & 0.0006 \\
Mean Glucose $(\mathrm{mg} / \mathrm{dL})$ & $103.25(91.58-122)$ & $121.00(99.75-147.25)$ & 0.0005 \\
Matsuda Index & $3.64(1.81-4.97)$ & $3.95(1.83-5.98)$ & $\mathrm{NS}$ \\
HOMA-IR score & $2.65(1.65-4.57)$ & $2.12(1.37-4.29)$ & $\mathrm{NS}$ \\
HOMA-\% $\beta$ & $222.56(169.70-346.50)$ & $109.31(82.33-167.74)$ & $<0.00001$ \\
Insulinogenic Index & $1.81(1.10-2.65)$ & $1.15(0.78-2.2)$ & 0.02 \\
Insulin 0' $(\mu \mathrm{IU} / \mathrm{mL})$ & $12.51(8.66-20.80)$ & $8.64(6.18-16.75)$ & 0.003 \\
Insulin 30' $(\mu \mathrm{IU} / \mathrm{mL})$ & $100(68.16-126.37)$ & $70.09(50.37-111.3)$ & 0.006 \\
Insulin 60' $(\mu \mathrm{IU} / \mathrm{mL})$ & $94(55.14-159.2)$ & $88.33(42.41-118.4)$ & $\mathrm{NS}$ \\
Insulin $120^{\prime}(\mu \mathrm{IU} / \mathrm{mL})$ & $48.8(22.76-103.60)$ & $33.57(25.82-94.52)$ & $\mathrm{NS}$ \\
Mean Insulin $(\mu \mathrm{IU} / \mathrm{mL})$ & $64.7(38.75-102.15)$ & $49.75(35.62-90.72)$ & $\mathrm{NS}$ \\
Matsuda-IR $n(\%)$ & $11(35.4 \%)$ & $10(32.2 \%)$ & $\mathrm{NS}$ \\
HOMA-IR $n(\%)$ & $17(54.8 \%)$ & $13(41.9 \%)$ & $\mathrm{NS}$ \\
\hline
\end{tabular}

Data are expressed as median (25-75\% quartiles) or numbers (\%). $p<0.05$ was considered statistically significant. Wilcoxon signed-rank test and the sign test were used to compare estimated variables at baseline and after follow-up. HOMA-IR, homeostasis model assessment of insulin resistance; HOMA- $\% \beta$, homeostasis model assessment of $\beta$-cell dysfunction; NS, non-significant.

$\Delta$ Fasting insulin was correlated with the initial value of fasting insulin and similarly, $\triangle \mathrm{HOMA}-\% \beta$ was correlated with the value of $\mathrm{HOMA}-\% \beta$ assessed at the baseline (respectively, $\mathrm{R}=-0.57, p=0.0008$; $\mathrm{R}=-0.88, p<0.0001)$. All the important correlations between glucose, insulin and markers of IR assessed at the end of the follow-up and selected anthropometric, metabolic and hormonal parameters are presented in Tables 5 and 6.

A significant relationship between IR and abnormal lipid profile was noted. Dyslipidaemia was found in $70 \%$ of the women who were diagnosed with IR according to Matsuda index and in $29 \%$ of the women who had not IR $(p=0.03)$, whereas a low concentration of HDL-c could be observed in $60 \%$ of the women with Matsuda-IR and in $9.52 \%$ of the women without IR $(p=0.003)$.

It is worth mentioning that a connection between IR and androgens was found. Matsuda-IR could be found in $63.64 \%$ of the women with an elevated value of FAI and only in $15 \%$ of the women with not elevated FAI $(p=0.006)$. Statistically significant correlations were found between final FAI and both initial and final Matsuda index (respectively, $\mathrm{R}=-0.53, p=0.002 ; \mathrm{R}=-0.45, p=0.01$ ). On the other hand, the women diagnosed with Matsuda-IR had significantly lower concentrations of adrenal androgen (17-OHP) compared to the women without IR (respectively, 1.08, IQr: 0.75-1.16 vs. 1.38, IQr: $0.98-1.59, p=0.004)$. We found 17-OHP to be almost significantly correlated with Matsuda index and fasting insulin (respectively, $\mathrm{R}=0.33, \mathrm{R}=-0.33$, all $p=0.07$ ).

\subsubsection{Incident Prediabetes}

After a median follow-up of 10 years, subsequent glucose load measurements revealed that $45 \%$ of the studied women developed preDM $(n=14)$. Of all the participants, $25.8 \%$ developed IFG $(n=8)$, whereas $19.35 \%$ developed IGT $(n=6)$. No one developed T2DM. Thus, the annualised incidence rate for conversion from normoglycaemic to preDM was $4.5 \%$, to IFG $-2.6 \%$ and to IGT $-1.9 \%$. Differences between women with normal and abnormal glucose tolerance are presented in Table 7. 
Table 5. Correlations between final concentrations of glucose, markers of insulin resistance and hyperinsulinaemia, with selected anthropometric, metabolic and hormonal parameters.

\begin{tabular}{|c|c|c|c|c|c|c|}
\hline \multirow{2}{*}{$\begin{array}{c}\text { Selected Baseline and Final Metabolic and } \\
\text { Hormonal Parameters }\end{array}$} & \multicolumn{6}{|c|}{ Final Glucose and Markers of Insulin Resistance } \\
\hline & Glucose $0^{\prime}(\mathrm{mg} / \mathrm{dL})$ & Glucose $120^{\prime}(\mathrm{mg} / \mathrm{dL})$ & Mean Glucose (mg/dL) & Matsuda Index & HOMA-IR Score & HOMA- $\% \beta$ \\
\hline Glucose $0^{\prime}$ at Baseline $(\mathrm{mg} / \mathrm{dL})$ & $0.47^{* *}$ & NS & NS & NS & $0.39 *$ & NS \\
\hline Glucose $120^{\prime}$ at Baseline (mg/dL) & $0.45 *$ & $0.52^{* *}$ & $0.49^{* *}$ & -0.40 * & 0.37 * & NS \\
\hline Mean glucose at Baseline (mg/dL) & $0.48^{* *}$ & $0.49^{* *}$ & $0.54^{* *}$ & $-0.41 *$ & $0.38^{*}$ & NS \\
\hline Matsuda Index at Baseline & $-0.56 * *$ & -0.53 ** & $-0.59 * * *$ & $0.75^{* * *}$ & $-0.71 * * *$ & $-0.63^{* * *}$ \\
\hline HOMA-IR Score at Baseline & $0.49^{* *}$ & $0.36 *$ & $0.43 *$ & $-0.67^{* * *}$ & $0.69^{* * *}$ & $0.48^{* *}$ \\
\hline HOMA- $\% \beta$ at Baseline & NS & NS & NS & $-0.36 *$ & NS & $0.41 *$ \\
\hline M-clamp Value at Baseline (mg/kgffm $/ \mathrm{min}$ ) & $-0.41 *$ & $-0.66^{* * *}$ & $-0.64 * * *$ & $0.71^{* * *}$ & $-0.68^{* * *}$ & $-0.63^{* * *}$ \\
\hline BMI at Follow-Up $\left(\mathrm{kg} / \mathrm{m}^{2}\right)$ & $0.67 * * *$ & $0.48^{* *}$ & $0.60^{* * *}$ & $-0.80 * * *$ & $0.85^{* * *}$ & $0.57 * * *$ \\
\hline BMI at Baseline $\left(\mathrm{kg} / \mathrm{m}^{2}\right)$ & $0.53 * *$ & $0.41 *$ & 0.51 ** & $-0.73 * * *$ & $0.81^{* * *}$ & $0.62 * * *$ \\
\hline Waist Circumference at Follow-Up (cm) & $0.66^{* * *}$ & $0.50^{* *}$ & $0.62^{* * *}$ & $-0.82 * * *$ & $0.84^{* * *}$ & $0.59^{* * *}$ \\
\hline Waist Circumference at Baseline $(\mathrm{cm})$ & $0.62 * * *$ & $0.48^{* *}$ & $0.66^{* * *}$ & $-0.83 * * *$ & $0.88^{* * *}$ & $0.61^{* * *}$ \\
\hline Fat Mass at Follow-Up (\%) & $0.67^{* * *}$ & $0.55^{* *}$ & $0.67^{* * *}$ & $-0.79 * * *$ & $0.82 * * *$ & $0.54^{* *}$ \\
\hline Fat mass at Baseline (\%) & $0.62 * * *$ & $0.48^{* *}$ & $0.63 * * *$ & $-0.73 * * *$ & $0.78^{* * *}$ & $0.50^{* *}$ \\
\hline Triglycerides at Follow-Up $(\mathrm{mg} / \mathrm{dL})$ & $0.68^{* * *}$ & $0.52 p=0.06$ & $0.67 * * *$ & $-0.79 * * *$ & $0.83^{* * *}$ & 0.52 ** \\
\hline Triglycerides at Baseline $(\mathrm{mg} / \mathrm{dL})$ & $0.40 *$ & $0.33 p=0.07$ & $0.43 *$ & $-0.46^{* *}$ & $0.59 * * *$ & $0.43 *$ \\
\hline HDL-c at Follow-Up (mg/dL) & $-0.61^{* * *}$ & $-0.35 \mathrm{p}=0.06$ & -0.39 * & $0.55^{* *}$ & $-0.65^{* * *}$ & NS \\
\hline HDL-c at Baseline ( $\mathrm{mg} / \mathrm{dL})$ & $-0.48^{* *}$ & $-0.34 p=0.06$ & $-0.35 \mathrm{p}=0.05$ & $0.50 * *$ & $-0.62 * * *$ & NS \\
\hline SHBG at Follow-Up (nmol/l) & $-0.48^{* *}$ & NS & NS & $0.56 * * *$ & $-0.58^{* * *}$ & $-0.35 \mathrm{p}=0.06$ \\
\hline SHBG at Baseline $(\mathrm{nmol} / \mathrm{l})$ & $-0.42 *$ & $-0.44 *$ & $-0.51 * *$ & $0.55^{* *}$ & $-0.60 * * *$ & $-0.44 *$ \\
\hline FAI at Follow-Up & $0.44 *$ & NS & NS & $-0.45 *$ & $0.47^{* *}$ & NS \\
\hline FAI at Baseline & 0.39 * & $0.52^{* *}$ & $0.56^{* *}$ & NS & $0.36^{p}=0.07$ & NS \\
\hline
\end{tabular}

Data are shown as $\mathrm{r}$ correlation coefficient. Significance levels are indicated by asterisks $\left({ }^{*}, p<0.05 ;{ }^{* *}, p<0.01 ; * * *, p<0.001\right)$. Correlation coefficients were estimated by Spearman's correlation for all parameters. BMI, body mass index; FAI, free androgen index; HDL-c, high-density lipoprotein cholesterol; HOMA-IR, homeostasis model assessment of insulin resistance; HOMA- $\% \beta$, homeostasis model assessment of $\beta$-cell dysfunction; M-clamp value, insulin sensitivity estimated with the euglycaemic hyperinsulinaemic clamp technique; NS, non-significant; SHBG, sex hormone-binding globulin. 
Table 6. Correlations between final concentrations of insulin and selected anthropometric, metabolic and hormonal parameters.

\begin{tabular}{|c|c|c|c|}
\hline \multirow{2}{*}{$\begin{array}{l}\text { Selected Baseline and Final Metabolic and } \\
\text { Hormonal Parameters }\end{array}$} & \multicolumn{3}{|c|}{ Final Insulin } \\
\hline & Insulin $0^{\prime}(\mu \mathrm{IU} / \mathrm{mL})$ & Insulin $120^{\prime}(\mu \mathrm{IU} / \mathrm{mL})$ & Mean Insulin $(\mu \mathrm{IU} / \mathrm{mL})$ \\
\hline Insulin $0^{\prime}$ at Baseline $(\mu \mathrm{IU} / \mathrm{mL})$ & $0.62 * * *$ & $0.52 * *$ & $0.61^{* * *}$ \\
\hline Insulin $120^{\prime}$ at Baseline $(\mu \mathrm{IU} / \mathrm{mL})$ & $0.46^{* *}$ & $0.60^{* * *}$ & $0.38^{*}$ \\
\hline Mean insulin at Baseline $(\mu \mathrm{IU} / \mathrm{mL})$ & $0.62^{* * *}$ & $0.62^{* * *}$ & $0.74^{* * *}$ \\
\hline M-clamp Value at Baseline (mg/kgffm/min) & $-0.71^{* * *}$ & $-0.67 * * *$ & $-0.67 * * *$ \\
\hline BMI at Follow-Up $\left(\mathrm{kg} / \mathrm{m}^{2}\right)$ & $0.83^{* * *}$ & $0.52 * *$ & $0.73^{* * *}$ \\
\hline BMI at Baseline $\left(\mathrm{kg} / \mathrm{m}^{2}\right)$ & $0.80^{* * *}$ & $0.45 *$ & $0.66^{* * *}$ \\
\hline Waist circumference at Follow-Up (cm) & $0.83^{* * *}$ & $0.57^{* * *}$ & $0.75^{* * *}$ \\
\hline Waist circumference at Baseline $(\mathrm{cm})$ & $0.87^{* * *}$ & $0.60^{* * *}$ & $0.74^{* * *}$ \\
\hline Fat mass at Follow-Up (\%) & $0.78^{* * *}$ & $0.61 * * *$ & $0.71^{* * *}$ \\
\hline Fat mass at Baseline (\%) & $0.74^{* * *}$ & $0.51^{* *}$ & $0.66^{* * *}$ \\
\hline Triglycerides at Follow-Up (mg/dL) & $0.79^{* * *}$ & $0.62^{* * *}$ & $0.70^{* * *}$ \\
\hline Triglycerides at Baseline $(\mathrm{mg} / \mathrm{dL})$ & $0.56^{* *}$ & $0.39 *$ & $0.38 *$ \\
\hline HDL-c at Follow-Up (mg/dL) & $-0.56^{* *}$ & $-0.45^{*}$ & $-0.52 * *$ \\
\hline HDL-c at Baseline (mg/dL) & $-0.56^{* *}$ & $-0.39 *$ & $-0.41 *$ \\
\hline SHBG at Follow-Up (nmol/l) & $-0.51^{* *}$ & $-0.50 * *$ & $-0.57^{* * *}$ \\
\hline SHBG at Baseline (nmol/l) & $-0.57 * * *$ & $-0.46^{* *}$ & $-0.46^{* *}$ \\
\hline FAI at Follow-Up & $0.42 *$ & $0.46^{* *}$ & $0.46^{* *}$ \\
\hline FAI at Baseline & $0.32^{p=0.08}$ & NS & NS \\
\hline
\end{tabular}

Data are shown as $\mathrm{r}$ correlation coefficient. Significance levels are indicated by asterisks $\left.{ }^{*}, p<0.05 ;{ }^{* *}, p<0.01 ; * * *, p<0.001\right)$. Correlation coefficients were estimated by Spearman's correlation for all parameters. BMI, body mass index; FAI, free androgen index; HDL-c, high-density lipoprotein cholesterol; M-clamp value, insulin sensitivity estimated with the euglycaemic hyperinsulinaemic clamp technique; NS, non-significant; SHBG, sex hormone-binding globulin. 
Table 7. Characteristics of the participants according to glucose metabolism.

\begin{tabular}{|c|c|c|c|}
\hline Characteristic & Normal Glucose Tolerance $(n=17)$ & Prediabetes $(n=14)$ & $p$-Value \\
\hline Age (years) & $34.7(30.2-37.3)$ & $38.2(34.4-43.8)$ & 0.07 \\
\hline BMI at Follow- $\mathrm{Up}\left(\mathrm{kg} / \mathrm{m}^{2}\right)$ & $22.14(20.83-24.8)$ & $32.58(27.13-39.12)$ & 0.003 \\
\hline BMI at Baseline $\left(\mathrm{kg} / \mathrm{m}^{2}\right)$ & $21.86(20.59-25.78)$ & $28.75(25.61-36.29)$ & 0.007 \\
\hline Waist circumference at Follow-Up $(\mathrm{cm})$ & $80(75-90)$ & $107(94-122)$ & 0.002 \\
\hline Waist circumference at Baseline $(\mathrm{cm})$ & $71(68-78)$ & $92.5(80-103)$ & 0.0007 \\
\hline Fat mass at Follow-Up (\%) & $27.7(22.7-32.7)$ & $44.2(33.9-48.4)$ & 0.002 \\
\hline Fat mass at Baseline (\%) & $28(24-32)$ & $41(34.5-46.5)$ & 0.002 \\
\hline Glucose $0^{\prime}$ at Follow-Up $(\mathrm{mg} / \mathrm{dL})$ & $90(87-91)$ & $103(101-108)$ & $<0.0001$ \\
\hline Glucose $0^{\prime}$ at Baseline $(\mathrm{mg} / \mathrm{dL})$ & $80(77-86)$ & $87(83-91.7)$ & 0.006 \\
\hline Glucose $120^{\prime}$ at Follow-Up $(\mathrm{mg} / \mathrm{dL})$ & $95(77-98)$ & 135 (118-159) & $<0.0001$ \\
\hline Glucose $120^{\prime}$ at Baseline $(\mathrm{mg} / \mathrm{dL})$ & $74(69-88)$ & $101.5(94-124)$ & 0.003 \\
\hline Mean glucose at Follow-Up (mg/dL) & $100.25(95-109.5)$ & $147.88(134.75-152)$ & $<0.0001$ \\
\hline Mean glucose at Baseline $(\mathrm{mg} / \mathrm{dL})$ & $98(89.75-102.25)$ & $120.46(110.50-126.75)$ & 0.002 \\
\hline Insulin $0^{\prime}$ at Follow-Up $(\mathrm{uIU} / \mathrm{mL})$ & $6.83(5.52-8.45)$ & $16.22(9.72-18.49)$ & 0.002 \\
\hline Insulin $0^{\prime}$ at Baseline $(\mathrm{uIU} / \mathrm{mL})$ & $10.53(7.4-14.54)$ & $16.18(11.7-24.48)$ & NS \\
\hline Insulin $120^{\prime}$ at Follow-Up (uIU/mL) & $26.85(18.09-31.82)$ & $85.12(45.86-149.26)$ & 0.0002 \\
\hline Insulin $120^{\prime}$ at Baseline $(\mathrm{uIU} / \mathrm{mL})$ & $29.21(22.76-63.59)$ & $85.76(42.82-120.06)$ & 0.04 \\
\hline Mean insulin at Follow-Up (uIU/mL) & $35.68(33.24-49.75)$ & $71.44(52.66-105.37)$ & 0.005 \\
\hline Mean insulin at Baseline (uIU/mL) & $52.93(37.55-64.7)$ & 88.79 (66.63-111.23) & 0.03 \\
\hline M-clamp value at Baseline $(\mathrm{mg} / \mathrm{kgffm} / \mathrm{min})$ & $9.61(8.4-11.62)$ & $5.68(4.15-8.44)$ & 0.01 \\
\hline Matsuda index at follow-up & $5.78(5.2-7.19)$ & $2.07(1.72-3.17)$ & 0.0004 \\
\hline Matsuda index at Baseline & $4.77(3.64-7.1)$ & $2.47(1.79-3.4)$ & 0.008 \\
\hline HOMA-IR score at follow-up & $1.48(1.11-1.82)$ & $3.87(2.42-5.06)$ & 0.0004 \\
\hline HOMA-IR score at Baseline & $2.24(1.36-2.86)$ & $3.49(2.51-5.07)$ & 0.04 \\
\hline HOMA- $\% \beta$ at follow-up & $95.96(75.56-138.34)$ & $129.67(90.31-178.16)$ & NS \\
\hline HOMA- $\% \beta$ at Baseline & $250.87(169.7-346.5)$ & $201.54(171-298.59)$ & NS \\
\hline HbA1c at Follow-Up (\%) & $5.2(5-5.4)$ & $5.3(5.1-5.5)$ & NS \\
\hline Triglycerides at Follow-Up (mg/dL) & $58(50-64)$ & $122(74-210)$ & 0.0002 \\
\hline Triglycerides at Baseline $(\mathrm{mg} / \mathrm{dL})$ & $74(51-86)$ & $126.5(76-172)$ & 0.02 \\
\hline LDL-c at Follow-Up (mg/dL) & $103.2(86-111.4)$ & $111.2(103.8-132.2)$ & 0.04 \\
\hline LDL-c at Baseline $(\mathrm{mg} / \mathrm{dL})$ & $91.8(78.2-100.8)$ & $109.7(86.0-139.8)$ & NS \\
\hline HDL-c at Follow-Up $(\mathrm{mg} / \mathrm{dL})$ & $70(66-85)$ & $47.5(42-69)$ & 0.005 \\
\hline HDL-c at Baseline (mg/dL) & $59(56-72)$ & $53(42-66)$ & 0.04 \\
\hline SHBG at Follow-Up (nmol/l) & $55.93(37.66-87.35)$ & $38.72(23.36-66.32)$ & 0.08 \\
\hline SHBG at Baseline (nmol/l) & $54.09(38.88-61.64)$ & $26.64(18.40-42.90)$ & 0.02 \\
\hline FAI at Follow-up & $2.23(1.36-3.90)$ & $5.4(2.20-9.50)$ & 0.08 \\
\hline FAI at Baseline & $3.87(3.44-5.24)$ & $9.84(4.63-11.66)$ & 0.003 \\
\hline
\end{tabular}

Data are expressed as median (25-75\% quartiles) or numbers (\%). $p<0.05$ was considered statistically significant. Variables were analysed by Mann-Whitney U-test. BMI, body mass index; FAI, free androgen index; HbA1c, glycated haemoglobin; HDL-c, high-density lipoprotein cholesterol; HOMA-IR, homeostasis model assessment of insulin resistance; HOMA- $\% \beta$, homeostasis model assessment of $\beta$-cell dysfunction; LDL-c, low-density lipoprotein cholesterol; M-clamp value, insulin sensitivity estimated with the euglycaemic hyperinsulinaemic clamp technique; NS, non-significant; SHBG, sex hormone-binding globulin. 
Of the women affected with preDM, $57 \%$ were obese, whereas $7.14 \%$ were normal weight. PreDM appeared in $76.47 \%$ of the women with final BMI $\geq 25 \mathrm{~kg} / \mathrm{m}^{2}$ and in $7.14 \%$ of the normal-weight women $(p=0.0001)$. On the other hand, preDM appeared in $70.59 \%$ of the women who had been overweight or obese and in $14.29 \%$ of the women who had been normal weight at the onset of the observation $(p=0.002)$, as also in $80 \%$ of the women who had had abdominal obesity $(\mathrm{WC} \geq 80 \mathrm{~cm})$ in the past and in $12.5 \%$ of the women who had not had abdominal obesity $(p=0.0002)$. Interestingly, all the women who developed preDM had WC $\geq 80 \mathrm{~cm}$ at the final examination. Another connection was found between preDM and previous insulin sensitivity. M-clamp value estimated as lower than median $(<8.438 \mathrm{mg} / \mathrm{kgffm} / \mathrm{min})$ was found in $71 \%$ of the women with preDM and in $29 \%$ of the women who stayed normoglycaemic $(p=0.02)$. It was also noted that preDM appeared more often in the women who had been diagnosed with MetS at the onset of the observation compared to those who had not fulfilled such criteria ( $35.71 \%$ vs. $5.88 \%, p=0.04)$.

Moreover, a connection was observed between HA noted at the beginning of the follow-up and later development of preDM. Almost $93 \%$ of the women with preDM de novo had been diagnosed with HA ten years earlier. On the other hand, preDM appeared in $63.16 \%$ of the women with previously elevated androgens and in $16.67 \%$ of the women without biochemical HA in the past $(p=0.01)$. The only significant difference in hormonal profile between the women with and without preDM concerned FAI.

Among 31 women with a previous diagnosis of PCOS the relationships between anthropometric, metabolic and hormonal parameters noted at the beginning of the observation and preDM found at the end of a 10-year follow-up period were assessed. The results show that BMI, FAI, fasting glucose and M-clamp value measured at the beginning of the observation are the most important predictors of preDM in PCOS women. All statistically significant predictors of preDM determined in logistic regression are presented in Table 8. SHBG measured at the onset of the observation was a marginally non-significant covariate associated with preDM (OR $=0.96 ; 95 \%$ CI: 0.93 to $1.0025, p=0.067)$.

Table 8. Significant predictors of prediabetes in women with a history of PCOS.

\begin{tabular}{ccccc}
\hline $\begin{array}{c}\text { Covariates-Parameters Stated at } \\
\text { the Beginning of the Follow-Up }\end{array}$ & OR & \multicolumn{2}{c}{$\mathbf{9 5 \%}$ CI for OR } & \multirow{2}{*}{-Value } \\
\cline { 3 - 4 } & & Lower & Upper & \\
\hline BMI $\left(\mathrm{kg} / \mathrm{m}^{2}\right)$ & 1.17 & 1.02 & 1.34 & 0.02 \\
Waist Circumference $(\mathrm{cm})$ & 1.09 & 1.02 & 1.16 & 0.01 \\
Glucose $0^{\prime}(\mathrm{mg} / \mathrm{dL})$ & 1.20 & 1.03 & 1.39 & 0.02 \\
Glucose $120^{\prime}(\mathrm{mg} / \mathrm{dL})$ & 1.07 & 1.02 & 1.13 & 0.008 \\
Glucose $120^{\prime}-0^{\prime}(\mathrm{mg} / \mathrm{dL})$ & 1.06 & 1.01 & 1.11 & 0.02 \\
Mean Glucose $(\mathrm{mg} / \mathrm{dL})$ & 1.10 & 1.03 & 1.18 & 0.005 \\
Insulin 120' (uIU/mL) & 1.02 & 1.003 & 1.04 & 0.02 \\
Insulin 120'-0' (uIU/mL) & 1.03 & 1.004 & 1.05 & 0.02 \\
M-clamp Value (mg/kgffm/min) & 0.73 & 0.56 & 0.95 & 0.02 \\
Triglycerides (mg/dL) & 1.02 & 1.004 & 1.05 & 0.02 \\
HDL-c (mg/dL) & 0.94 & 0.88 & 0.99 & 0.04 \\
FAI & 1.42 & 1.09 & 1.86 & 0.01 \\
\hline
\end{tabular}

Univariate logistic regression. Values are ORs (with 95\% CI) and reflect the associations of prediabetes risk with investigated variables. $p<0.05$ was considered statistically significant. BMI, body mass index; CI, confidence interval; FAI, free androgen index; HDL-c, high-density lipoprotein cholesterol; M-clamp value, insulin sensitivity estimated with the euglycaemic hyperinsulinaemic clamp technique; OR, odds ratio.

\section{Discussion}

The main finding of our study is the observation that the anthropometric and metabolic parameters assessed in young women with PCOS and ten years after are significantly correlated. This demonstrates that without the early therapeutic intervention in the affected subjects the adverse course of the metabolic changes will be continuing.

During the follow-up, we observed a spontaneous increase in the glucose concentrations, a decrease in the insulin concentrations and no changes in the indices of IR. Similar results were obtained by several authors [47-50]. This confirms the hypothesis that insulin sensitivity in patients with PCOS 
remains unchanged, whereas $\beta$-cell function decreases over time, which might be a result of ageing and exhaustion of pancreatic cells compensating IR over the long term.

The results of our study confirm a high risk of abnormal glucose tolerance in overweight/obese women with diagnosed PCOS [51]. The recently published data from the multi-centre national population health examination survey (WOBASZ) revealed that the prevalence of IFG in the cohort of Polish women aged 20-34 years totals $4.3 \%$, which is much lower than in our PCOS cohort (25.8\%) [52]. Available data concerning the development of preDM in PCOS women are limited. Pesant et al. reported an $8.8 \%$ annual conversion rate to abnormal glucose tolerance [48], but the mean BMI of the participants was $33.8 \mathrm{~kg} / \mathrm{m}^{2}$-markedly higher compared to our cohort. Furthermore, we determined that BMI, glucose and insulin concentrations, IR, FAI and levels of TG and HDL-c are important risk factors for abnormal glucose tolerance in women with PCOS and these results confirm the previous reports [48,53-55]. Recent research emphasises the association between the diet and clinical severity of PCOS and indicates the Mediterranean diet as a primary preventive and therapeutic tool in women with PCOS, weakening insulin resistance and eventually promoting improvements of reproductive life and endocrine outcomes [56].

We demonstrate strong correlations in women with PCOS between SHBG and components of MetS, like obesity, lipid profile, IR and preDM, and that is in line with the studies performed both in PCOS women and the general population [53,57]. It seems that the main role in the relationship between HA presented as FAI and metabolic complications is played by SBHG, not by TT. Not surprisingly, SHBG is proposed as a clinically useful marker of IR and metabolic status in PCOS [13]. We confirm that the measurement of SHBG may have a role in the early identification of individuals at a high risk of abnormal glucose metabolism. Although HA is associated with an adverse metabolic phenotype in PCOS patients, previous studies have shown that DHEAS may have positive effects on fat distribution and IR in women with PCOS [58-60]. In our study, the negative connections are presented between both 17-OHP and obesity and 17-OHP and IR. However, because of the lack of similar reports, the relationship between 17-OHP and adverse metabolic outcomes requires more research.

We report a high prevalence of obesity and overweight in the PCOS cohort (respectively, 29\% and $26 \%$ ) in comparison with the general population of young Polish women (respectively, $6 \%$ and $14 \%$ ) [52], and a significant increase in BMI, WC and the percentage of women with obesity, during the follow-up. Available data concerning the changes in anthropometric parameters in PCOS women are inconsistent. Significant increase as well as no changes in WC and BMI have been described [47,50,61,62]. This discrepancy may be caused by the differences in ethnicity and treatment strategies applied during the follow-up [63]. Nevertheless, we noticed no changes in BP and lipid concentrations in the studied women and the same results were obtained by the authors of the studies with similar duration of the follow-up $[50,64,65]$. A significant increase in the level of LDL-c was described in the studies with an over 20-year observation [49,62].

There are a number of limitations to the present study. Obviously, the main limitation is the small cohort size, which is connected with two factors. The first one is the fact of the restrictive inclusion criteria for the study. The number of women with PCOS and conducted clamp study was limited. The second one is a relatively high drop-out rate (66\%). However, a comparable percentage can be found in similar studies [66]. The women who participated in the first examination were in their twenties and during ten years of the follow-up, some of them changed their names, phone numbers and addresses. A sudden increase in labour migration at the beginning of the 21st century had an additional impact on the fact, that some of the examined women stayed abroad and their re-evaluation was not possible. Another potential limitation is the fact that the sample was recruited from an outpatient clinic setting. We are aware that this cohort may contain women with more severe disease compared to the entire community. Consecutive shortcomings of this analysis are lack of controls, lack of information about lifestyle and dietetic habits among the participants, and the fact that at the follow-up, we used surrogate markers for assessing IR (HOMA score and Matsuda index)—not a gold 
standard clamp method. Additionally, a period of three months of withdrawal of hormonal therapy could be potentially insufficient to ensure "neutral" metabolic state.

However, our study also has a number of strengths, including the longitudinal design, appropriately diagnosed PCOS in the studied cohort, detailed biochemical assessment and comparable endocrine status in participating subjects. Another strength of this research is the fact that the same qualified person measured all the anthropometric parameters and recorded clinical data. Furthermore, it is one of the few longitudinal studies in which data concerning insulin sensitivity determined with a clamp technique in the women with PCOS are used. To our knowledge, it is the first longitudinal study of women with PCOS in which body fat was assessed by bioelectric impedance analysis both at the beginning and at the end of the follow-up.

We acknowledge that at the end of the follow-up observation, the studied cohort is still young and thus we can discuss only the increased risk rather than actual metabolic and cardiovascular consequences in our PCOS group. Further observation of an extended cohort is warranted to assess the development of type 2 diabetes and cardiovascular complications.

In conclusion, the study gives more insight into the metabolic changes in women with PCOS. In patients with PCOS, $\beta$-cell function decreases with age, whereas insulin sensitivity remains unchanged. PCOS women are at a high risk of preDM. Obesity, IR, fasting glucose and HA expressed as FAI are the most important predictors of glucose metabolism deterioration after the years of PCOS diagnosis. Serum SHBG is associated with metabolic complications and long-term prognosis in women with PCOS. A relationship between 17-OHP and metabolic outcomes requires further research.

Author Contributions: Conceptualization, M.J.-Ś. and I.K.; methodology, I.K. and M.J.-Ś.; writing-original draft preparation, M.J.-Ś.; supervision, I.K. All authors have read and agreed to the published version of the manuscript. Funding: This research was funded by Medical University of Bialystok, grant number N/ST/ZB/16/006/1150.

Acknowledgments: We thank R. Milewski, statistician, for advice on data statistical analysis and the staff of the laboratory in the Department of Endocrinology, Diabetology and Internal Medicine, Medical University of Bialystok, Poland, for their invaluable work.

Conflicts of Interest: The authors declare no conflict of interest.

\section{References}

1. Bozdag, G.; Mumusoglu, S.; Zengin, D.; Karabulut, E.; Yildiz, B.O. The prevalence and phenotypic features of polycystic ovary syndrome: A systematic review and meta-analysis. Hum. Reprod. 2016, 31, 2841-2855. [CrossRef] [PubMed]

2. Engmann, L.L.; Jin, S.; Sun, F.; Legro, R.S.; Polotsky, A.J.; Hansen, K.R.; Coutifaris, C.; Diamond, M.P.; Eisenberg, E.; Zhang, H.; et al. Racial and ethnic differences in the polycystic ovary syndrome metabolic phenotype. Am. J. Obstet. Gynecol. 2017, 216, 493.e1-493.e13. [CrossRef] [PubMed]

3. Ding, T.; Hardiman, P.J.; Petersen, I.; Wang, F.F.; Qu, F.; Baio, G. The prevalence of polycystic ovary syndrome in reproductive-aged women of different ethnicity: A systematic review and meta-analysis. Oncotarget 2017, 8, 96351-96358. [CrossRef] [PubMed]

4. Group Rotterdam ESHRE/ASRM-Sponsored PCOS Consensus Workshop. Revised 2003 consensus on diagnostic criteria and long-term health risks related to polycystic ovary syndrome. Fertil. Steril. 2004, 81, 19-25. [CrossRef] [PubMed]

5. Rosenfield, R.L.; Ehrmann, D.A. The Pathogenesis of Polycystic Ovary Syndrome (PCOS): The Hypothesis of PCOS as Functional Ovarian Hyperandrogenism Revisited. Endocr. Rev. 2016, 37, 467-520. [CrossRef] [PubMed]

6. De Melo, A.S.; Dias, S.V.; Cavalli, R.D.C.; Cardoso, V.C.; Bettiol, H.; Barbieri, M.A.; Ferriani, R.A.; Vieira, C.S.; Melo, A.S. Pathogenesis of polycystic ovary syndrome: Multifactorial assessment from the foetal stage to menopause. Reproduction 2015, 150, R11-R24. [CrossRef] [PubMed]

7. Ajmal, N.; Khan, S.Z.; Shaikh, R. Polycystic ovary syndrome (PCOS) and genetic predisposition: A review article. Eur. J. Obstet. Gynecol. Reprod. Biol. X 2019, 3, 100060. [CrossRef] [PubMed] 
8. Day, F.; Karaderi, T.; Jones, M.R.; Meun, C.; He, C.; Drong, A.; Kraft, P.; Lin, N.; Huang, H.; Broer, L.; et al. Large-scale genome-wide meta-analysis of polycystic ovary syndrome suggests shared genetic architecture for different diagnosis criteria. PLoS Genet. 2018, 14, e1007813. [CrossRef] [PubMed]

9. Barrea, L.; Marzullo, P.; Muscogiuri, G.; di Somma, C.; Scacchi, M.; Orio, F.; Aimaretti, G.; Colao, A.; Savastano, S. Source and amount of carbohydrate in the diet and inflammation in women with polycystic ovary syndrome. Nutr. Res. Rev. 2018, 31, 291-301. [CrossRef] [PubMed]

10. Diamanti-Kandarakis, E.; Dunaif, A. Insulin Resistance and the Polycystic Ovary Syndrome Revisited: An Update on Mechanisms and Implications. Endocr. Rev. 2012, 33, 981-1030. [CrossRef] [PubMed]

11. Legro, R.S.; Castracane, V.D.; Kauffman, R.P. Detecting Insulin Resistance in Polycystic Ovary Syndrome: Purposes and Pitfalls. Obstet. Gynecol. Surv. 2004, 59, 141-154. [CrossRef] [PubMed]

12. Stepto, N.K.; Cassar, S.; Joham, A.E.; Hutchison, S.K.; Harrison, C.L.; Goldstein, R.F.; Teede, H.J. Women with polycystic ovary syndrome have intrinsic insulin resistance on euglycaemic-hyperinsulaemic clamp. Hum. Reprod. 2013, 28, 777-784. [CrossRef] [PubMed]

13. Cassar, S.; Misso, M.L.; Hopkins, W.G.; Shaw, C.S.; Teede, H.J.; Stepto, N.K. Insulin resistance in polycystic ovary syndrome: A systematic review and meta-analysis of euglycaemic-hyperinsulinaemic clamp studies. Hum. Reprod. 2016, 31, 2619-2631. [CrossRef] [PubMed]

14. Greenhill, C. Mechanisms of insulin resistance. Nat. Rev. Endocrinol. 2018, 14, 565. [CrossRef] [PubMed]

15. Obermayer-Pietsch, B.; Trummer, C.; Schwetz, V.; Schweighofer, N.; Pieber, T. Genetics of insulin resistance in polycystic ovary syndrome. Curr. Opin. Clin. Nutr. Metab. Care 2015, 18, 401-406. [CrossRef] [PubMed]

16. Teede, H.J.; Deeks, A.; Moran, L. Polycystic ovary syndrome: A complex condition with psychological, reproductive and metabolic manifestations that impacts on health across the lifespan. BMC Med. 2010, 8, 41. [CrossRef] [PubMed]

17. Rojas, J.; Chávez, M.; Olivar, L.; Rojas, M.; Morillo, J.; Mejías, J.; Calvo, M.; Bermúdez, V. Polycystic Ovary Syndrome, Insulin Resistance, and Obesity: Navigating the Pathophysiologic Labyrinth. Int. J. Reprod. Med. 2014, 2014, e719050. [CrossRef] [PubMed]

18. Anagnostis, P.; Tarlatzis, B.C.; Kauffman, R.P. Polycystic ovarian syndrome (PCOS): Long-term metabolic consequences. Metabolism 2018, 86, 33-43. [CrossRef] [PubMed]

19. Lim, S.; Davies, M.; Norman, R.J.; Moran, L. Overweight, obesity and central obesity in women with polycystic ovary syndrome: A systematic review and meta-analysis. Hum. Reprod. Updat. 2012, 18, 618-637. [CrossRef] [PubMed]

20. Glueck, C.J.; Goldenberg, N. Characteristics of obesity in polycystic ovary syndrome: Etiology, treatment, and genetics. Metabolism 2019, 92, 108-120. [CrossRef] [PubMed]

21. Lim, S.S.; Norman, R.J.; Davies, M.J.; Moran, L.J. The effect of obesity on polycystic ovary syndrome: A systematic review and meta-analysis. Obes. Rev. 2012, 14, 95-109. [PubMed]

22. Kakoly, N.S.; Earnest, A.; Teede, H.J.; Moran, L.J.; Joham, A.E. The Impact of Obesity on the Incidence of Type 2 Diabetes among Women with Polycystic Ovary Syndrome. Diabetes Care 2019, 42, 560-567. [PubMed]

23. Capozzi, A.; Scambia, G.; Lello, S. Polycystic ovary syndrome (PCOS) and adolescence: How can we manage it? Eur. J. Obstet. Gynecol. Reprod. Biol. 2020, 250, 235-240. [PubMed]

24. Patel, S. Polycystic ovary syndrome (PCOS), an inflammatory, systemic, lifestyle endocrinopathy. J. Steroid Biochem. Mol. Biol. 2018, 182, 27-36. [PubMed]

25. Legro, R.S.; Kunselman, A.R.; Dodson, W.C.; Dunaif, A. Prevalence and Predictors of Risk for Type 2 Diabetes Mellitus and Impaired Glucose Tolerance in Polycystic Ovary Syndrome: A Prospective, Controlled Study in 254 Affected Women1. J. Clin. Endocrinol. Metab. 1999, 84, 165-169. [PubMed]

26. Kakoly, N.S.; Khomami, M.B.; E Joham, A.; Cooray, S.D.; Misso, M.L.; Norman, R.J.; Harrison, C.L.; Ranasinha, S.; Teede, H.J.; Moran, L.J. Ethnicity, obesity and the prevalence of impaired glucose tolerance and type 2 diabetes in PCOS: A systematic review and meta-regression. Hum. Reprod. Updat. 2018, 24, 455-467. [PubMed]

27. Wild, R.A.; Rizzo, M.; Clifton, S.; Carmina, E. Lipid levels in polycystic ovary syndrome: Systematic review and meta-analysis. Fertil. Steril. 2011, 95, 1073-1079. [PubMed] 
28. Legro, R.S.; Kunselman, A.R.; Dunaif, A. Prevalence and predictors of dyslipidemia in women with polycystic ovary syndrome. Am. J. Med. 2001, 111,607-613. [PubMed]

29. Wild, R.A.; Painter, P.C.; Coulson, P.B.; Carruth, K.B.; Ranney, G.B. Lipoprotein Lipid Concentrations and Cardiovascular Risk in Women with Polycystic Ovary Syndrome. J. Clin. Endocrinol. Metab. 1985, 61, 946-951. [PubMed]

30. Joham, A.E.; Boyle, J.A.; Zoungas, S.; Teede, H.J. Hypertension in Reproductive-Aged Women with Polycystic Ovary Syndrome and Association with Obesity. Am. J. Hypertens. 2014, 28, 847-851. [PubMed]

31. Shi, Y.; Cui, Y.; Sun, X.; Ma, G.; Ma, Z.; Gao, Q.; Chen, Z.J. Hypertension in women with polycystic ovary syndrome: Prevalence and associated cardiovascular risk factors. Eur. J. Obstet. Gynecol. Reprod. Biol. 2014, 173, 66-70. [CrossRef] [PubMed]

32. Moran, L.; Misso, M.L.; Wild, R.A.; Norman, R.J. Impaired glucose tolerance, type 2 diabetes and metabolic syndrome in polycystic ovary syndrome: A systematic review and meta-analysis. Hum. Reprod. Updat. 2010, 16, 347-363. [CrossRef] [PubMed]

33. Coviello, A.D.; Legro, R.S.; Dunaif, A. Adolescent Girls with Polycystic Ovary Syndrome Have an Increased Risk of the Metabolic Syndrome Associated with Increasing Androgen Levels Independent of Obesity and Insulin Resistance. J. Clin. Endocrinol. Metab. 2006, 91, 492-497. [CrossRef] [PubMed]

34. Rizzo, M.; Berneis, K.; Spinas, G.; Rini, G.B.; Carmina, E. Long-term consequences of polycystic ovary syndrome on cardiovascular risk. Fertil. Steril. 2009, 91, 1563-1567. [CrossRef] [PubMed]

35. Jacewicz-Święcka, M.; Kowalska, I. Polycystic ovary syndrome and the risk of cardiometabolic complications in longitudinal studies. Diabetes/Metabolism Res. Rev. 2018, 34, e3054. [CrossRef] [PubMed]

36. Kowalska, I.; Straczkowski, M.; Nikołajuk, A.; Adamska, A.; Karczewska-Kupczewska, M.; Otziomek, E.; Wolczyński, S.; Gorska, M. Serum visfatin in relation to insulin resistance and markers of hyperandrogenism in lean and obese women with polycystic ovary syndrome. Hum. Reprod. 2007, 22, 1824-1829. [CrossRef] [PubMed]

37. DeFronzo, R.A.; Tobin, J.D.; Andres, R. Glucose clamp technique: A method for quantifying insulin secretion and resistance. Am. J. Physiol. Metab. 1979, 237, E214-E223. [CrossRef] [PubMed]

38. Straczkowski, M.; Kowalska, I.; Nikolajuk, A.; Dzienis-Straczkowska, S.; Kinalska, I.; Baranowski, M.; Zendzian-Piotrowska, M.; Brzezinska, Z.; Gorski, J. Relationship Between Insulin Sensitivity and Sphingomyelin Signaling Pathway in Human Skeletal Muscle. Diabetes 2004, 53, 1215-1221. [CrossRef] [PubMed]

39. Ma, W.Y.; Yang, C.Y.; Shih, S.R.; Hsieh, H.J.; Hung, C.S.; Chiu, F.C.; Lin, M.S.; Liu, P.H.; Hua, C.H.; Hsein, Y.C.; et al. Measurement of Waist Circumference. Diabetes Care 2013, 36, 1660-1666. [CrossRef] [PubMed]

40. Matthews, D.R.; Hosker, J.P.; Rudenski, A.S.; Naylor, B.A.; Treacher, D.F.; Turner, R.C. Homeostasis model assessment: Insulin resistance and ?-cell function from fasting plasma glucose and insulin concentrations in man. Diabetologia 1985, 28, 412-419. [CrossRef] [PubMed]

41. Matsuda index. Available online: http://mmatsuda.diabetes-smc.jp/english.htm/ (accessed on 18 October 2020).

42. Vermeulen, A.; Verdonck, L.; Kaufman, J.M. A Critical Evaluation of Simple Methods for the Estimation of Free Testosterone in Serum. J. Clin. Endocrinol. Metab. 1999, 84, 3666-3672. [CrossRef] [PubMed]

43. Teede, H.J.; Misso, M.L.; Costello, M.F.; Dokras, A.; Laven, J.; Moran, L.; Piltonen, T.; Norman, R.J.; Andersen, M.; Azziz, R.; et al. Recommendations from the international evidence-based guideline for the assessment and management of polycystic ovary syndrome. Hum. Reprod. 2018, 33, 1602-1618. [CrossRef] [PubMed]

44. WHO. Obesity: Preventing and Managing the Global Epidemic. Report of a WHO Consultation; World Health Organ Tech Rep Ser. WHO: Geneva, Switzerland, 2000; Volume 894, pp. 1-253. [PubMed]

45. Mellitus, D. American Diabetes Association Diagnosis and Classification of Diabetes Mellitus. Diabetes Care 2012, 36, S67-S74. [PubMed]

46. Alberti, K.G.M.M.; Zimmet, P.; Shaw, J. The metabolic syndrome-A new worldwide definition. Lancet 2005, 366, 1059-1062. [CrossRef] [PubMed] 
47. Hudecova, M.; Holte, J.; Moby, L.; Olovsson, M.; Stridsberg, M.; Larsson, A.; Berglund, L.; Berne, C.; Poromaa, I.S. Androgen levels, insulin sensitivity, and early insulin response in women with polycystic ovary syndrome: A long-term follow-up study. Fertil. Steril. 2011, 95, 1146-1148. [CrossRef] [PubMed]

48. Pesant, M.H.; Baillargeon, J.P. Clinically useful predictors of conversion to abnormal glucose tolerance in women with polycystic ovary syndrome. Fertil. Steril. 2011, 95, 210-215. [CrossRef] [PubMed]

49. Carmina, E.; Campagna, A.M.; Lobo, R.A. Emergence of ovulatory cycles with aging in women with polycystic ovary syndrome (PCOS) alters the trajectory of cardiovascular and metabolic risk factors. Hum. Reprod. 2013, 28, 2245-2252. [CrossRef] [PubMed]

50. Tehrani, F.R.; Montazeri, S.A.; Hosseinpanah, F.; Cheraghi, L.; Erfani, H.; Tohidi, M.; Azizi, F. Trend of Cardio-Metabolic Risk Factors in Polycystic Ovary Syndrome: A Population-Based Prospective Cohort Study. PLoS ONE 2015, 10, e0137609. [PubMed]

51. Ollila, M.M.; West, S.; Keinänen-Kiukaanniemi, S.; Jokelainen, J.; Auvinen, J.; Puukka, K.; Ruokonen, A.; Järvelin, M.R.; Tapanainen, J.; Franks, S.; et al. Overweight and obese but not normal weight women with PCOS are at increased risk of Type 2 diabetes mellitus-A prospective, population-based cohort study. Hum. Reprod. 2016, 32, 423-431. [CrossRef] [PubMed]

52. Rutkowski, M.; Wojciechowska, A.; Śmigielski, W.; Drygas, W.; Piwońska, A.; Pajak, A.; Tykarski, A.; Kozakiewicz, K.; Waśniewska, M.K.; Zdrojewski, T. Prevalence of diabetes and impaired fasting glucose in Poland in 2005-2014: Results of the WOBASZ surveys. Diabet. Med. 2020, 37, 1528-1535. [CrossRef] [PubMed]

53. Gambineri, A.; Patton, L.; Altieri, P.; Pagotto, U.; Pizzi, C.; Manzoli, L.; Pasquali, R. Polycystic Ovary Syndrome Is a Risk Factor for Type 2 Diabetes: Results From a Long-Term Prospective Study. Diabetes 2012, 61, 2369-2374. [CrossRef] [PubMed]

54. Velija-Asimi, Z.; Burekovic, A.; Dujic, T.; Dizdarevic-Bostandzic, A.; Semiz, S. Incidence of prediabetes and risk of developing cardiovascular disease in women with polycystic ovary syndrome. Bosn. J. Basic Med Sci. 2016, 16, 298-306. [CrossRef] [PubMed]

55. Rubin, K.H.; Glintborg, D.; Nybo, M.; Abrahamsen, B.; Andersen, M. Development and Risk Factors of Type 2 Diabetes in a Nationwide Population of Women with Polycystic Ovary Syndrome. J. Clin. Endocrinol. Metab. 2017, 102, 3848-3857. [PubMed]

56. Barrea, L.; Arnone, A.; Annunziata, G.; Muscogiuri, G.; Laudisio, D.; Salzano, C.; Pugliese, G.; Colao, A.; Savastano, S. Adherence to the Mediterranean Diet, Dietary Patterns and Body Composition in Women with Polycystic Ovary Syndrome (PCOS). Nutrients 2019, 11, 2278. [PubMed]

57. Ding, E.L.; Song, Y.; Manson, J.E.; Hunter, D.J.; Lee, C.C.; Rifai, N.; Buring, J.E.; Gaziano, J.M.; Liu, S. Sex Hormone-Binding Globulin and Risk of Type 2 Diabetes in Women and Men. N. Engl. J. Med. 2009, 361, 1152-1163. [PubMed]

58. Lerchbaum, E.; Schwetz, V.; Giuliani, A.; Pieber, T.; Obermayer-Pietsch, B. Opposing effects of dehydroepiandrosterone sulfate and free testosterone on metabolic phenotype in women with polycystic ovary syndrome. Fertil. Steril. 2012, 98, 1318-1325.e1. [PubMed]

59. Brennan, K.; Huang, A.; Azziz, R. Dehydroepiandrosterone sulfate and insulin resistance in patients with polycystic ovary syndrome. Fertil. Steril. 2009, 91, 1848-1852. [PubMed]

60. Chen, M.J.; Chen, C.D.; Yang, J.H.; Ho, H.N.; Yang, W.S.; Yang, Y.S.; Chen, C.D.; Chen, C.L. High serum dehydroepiandrosterone sulfate is associated with phenotypic acne and a reduced risk of abdominal obesity in women with polycystic ovary syndrome. Hum. Reprod. 2010, 26, 227-234. [PubMed]

61. Carmina, E.; Campagna, A.M.; Lobo, R.A. A 20-Year Follow-up of Young Women with Polycystic Ovary Syndrome. Obstet. Gynecol. 2012, 119, 263-269. [CrossRef] [PubMed]

62. Schmidt, J.; Landin-Wilhelmsen, K.; Brännström, M.; Dahlgren, E. Cardiovascular Disease and Risk Factors in PCOS Women of Postmenopausal Age: A 21-Year Controlled Follow-Up Study. J. Clin. Endocrinol. Metab. 2011, 96, 3794-3803. [PubMed]

63. Ezeh, U.; Chen, Y.I.; Azziz, R. Racial and ethnic differences in the metabolic response of polycystic ovary syndrome. Clin. Endocrinol. 2020. [CrossRef] [PubMed]

64. Pasquali, R.; Gambineri, A.; Anconetani, B.; Vicennati, V.; Colitta, D.; Caramelli, E.; Casimirri, F.; Morselli-Labate, A.M. The natural history of the metabolic syndrome in young women with the polycystic ovary syndrome and the effect of long-term oestrogen-progestagen treatment. Clin. Endocrinol. 1999, 50, 517-527. [CrossRef] [PubMed] 
65. Dovom, M.R.; Tehrani, F.R.; Djalalinia, S.; Cheraghi, L.; Gandavani, S.B.; Azizi, F. Menstrual Cycle Irregularity and Metabolic Disorders: A Population-Based Prospective Study. PLoS ONE 2016, 11, e0168402. [PubMed]

66. Andries, M.; Glintborg, D.; Andersen, M. Risk of impaired glucose tolerance in normal weight hirsute women during four years observation. Acta Obstet. Gynecol. Scand. 2010, 89, 1091-1095. [CrossRef] [PubMed]

Publisher's Note: MDPI stays neutral with regard to jurisdictional claims in published maps and institutional affiliations.

(C) 2020 by the authors. Licensee MDPI, Basel, Switzerland. This article is an open access article distributed under the terms and conditions of the Creative Commons Attribution (CC BY) license (http://creativecommons.org/licenses/by/4.0/). 